\title{
LA INCIDENCIA DEL \\ NARCOTRÁFICO EN LAS ALTAS ESFERAS DEL GOBIERNO PERUANO
}

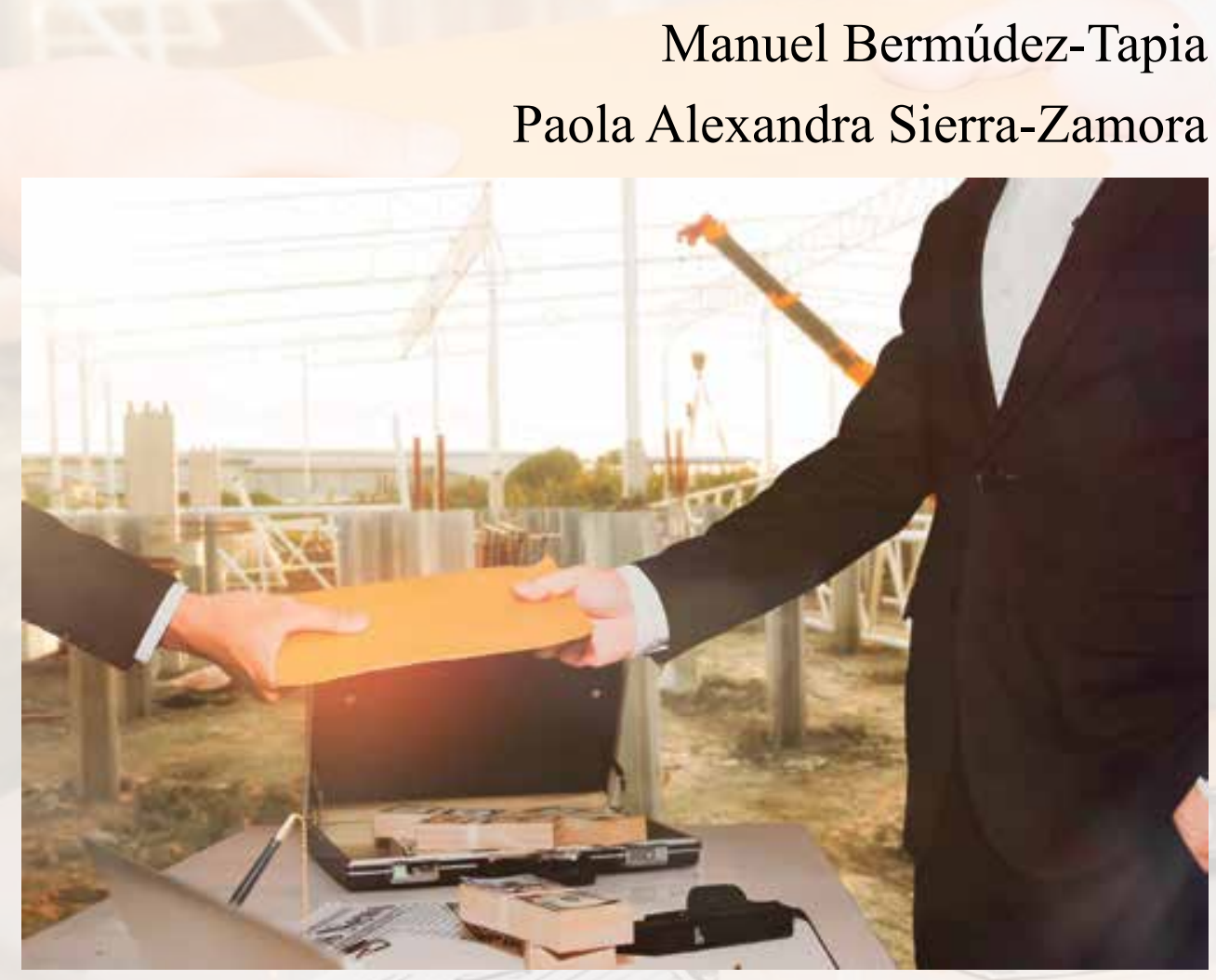





\title{
LA INCIDENCIA DEL NARCOTRÁFICO EN LAS ALTAS ESFERAS DEL GOBIERNO PERUANO*
}

\author{
Manuel Bermúdez-TaPia \\ Universidad Privada San Juan Bautista \\ Paola Alexandra Sierra-Zamora \\ Universidad Católica de Colombia
}

\section{Resumen}

Desde mediados de los años ochenta del siglo pasado hasta la actualidad, el narcotráfico ha tenido un severo impacto económico, político y social en el Perú. En el año 2018, producto de una investigación policial-fiscal, se descubrió la relación entre una banda de narcotraficantes con algunos funcionarios del poder Judicial, del Ministerio Público y del Consejo Nacional de la Magistratura, quienes tenían vínculos cercanos en las demás entidades del Estado, lo que acreditó la presencia de tales agentes en las altas esferas del poder. Las consecuencias han debilitado la democracia en el país, porque las influencias del narcotráfico podían relacionarse con miembros del Congreso de la República e inclusive del Gobierno nacional. Entonces, el Estado ejecutó una serie de acciones normativas e institucionales para limitar la influencia del narcotráfico y modificó la legislación penal-civil que regula el control financiero y bancario y la disposición de bienes inmuebles ligados a casos de lavado de activos; desactivó el Consejo Nacional de la Magistratura y destituyó a la mayoría de los funcionarios de altas corporaciones judiciales del país.

Palabras clave: Estado, administración pública, gobernabilidad, política, legislación y economía, servicio de justicia, poder Judicial, Consejo Nacional de la Magistratura, narcotráfico, lavado de activos, criminalidad organizada.

Artículo de investigación que expone resultados del proyecto titulado: "Desafíos contemporáneos para la protección de derechos humanos en escenarios de posconflicto desde enfoques interdisciplinarios", fase III. Forma parte de la línea de investigación Fundamentación e implementación de los derechos humanos, del grupo de investigación Persona, instituciones y exigencias de justicia, reconocido y categorizado como tipo Al por Minciencias y registrado con el código COL0120899, vinculado al Centro de Investigaciones Sociojurídicas de la Universidad Católica de Colombia (Cisjuc), adscrito a la Facultad de Derecho de la Universidad Católica de Colombia y financiado por el Departamento Administrativo de Ciencia, Tecnología e Innovación Minciencias. 
Los autores: Manuel Bermúdez-Tapia, abogado graduado con la mención de Summa Cumme Laude por la Pontificia Universidad Católica del Perú. Magister en Derecho. Profesor Investigador de la Universidad Privada San Juan Bautista y profesor de la Facultad de Derecho de la Universidad Nacional Mayor de San Marcos. Correo electrónico: manuel.bermudez@upsjb.edu.pe Código RENACYT PO140233. http://orcid.org/0000-0003-1576-9464

Paola Alexandra Sierra-Zamora, PhD Internacional en Derechos Humanos, Democracia y Justicia Internacional por la Universitat de Valéncia. Magister en Derechos Humanos, Democracia y Justicia Internacional por la misma casa de estudios. Abogada de la Universidad Católica de Colombia. Correo: pasierra@ucatolica.edu.co https://orcid.org/0000-0002-3146-7418

Recibido: 6 de junio de 2020; evaluado: 8 de marzo de 2021; aceptado: 8 de abril de 2021. 


\title{
THE INCIDENCE OF DRUG TRAFFICKING IN THE UPPER ECHELONS OF THE PERUVIAN GOVERNMENT
}

\author{
Manuel Bermúdez-TaPia \\ Universidad Privada San Juan Bautista \\ Paola Alexandra Sierra-Zamora \\ Universidad Católica de Colombia
}

\begin{abstract}
From the mid-eighties of the last century to the present, drug trafficking has generated a severe economic, political and social impact in Peru. In 2018, as a result of a police prosecutor's investigation, the relationship between a gang of drug traffickers with some officials of the Judicial Power, Public Ministry and National Council of the Magistracy, who had close ties in the other State entities, was discovered, which accredited the presence of such agents linked to drug trafficking in the high spheres of power. The consequences have weakened democracy in the country because the influence of drug trafficking could be related to members of the Congress of the Republic and even the national government. Consequently, the State implemented a series of normative and institutional actions to limit the influence of drug trafficking and modified the criminal-civil legislation that regulates financial and banking control and the disposition of real estate linked to money laundering cases, deactivating the National Council of the Magistracy and dismissing the majority of officials from high judicial entities in the country.
\end{abstract}

Keywords: State, public administration, governance, politics, legislation and economics, justice service, judiciary, National Council of the Magistracy, drug trafficking, money laundering, organized crime. 
The authors: Lawyer graduated Summa Cumme Laude from the Pontificia Universidad Católica del Perú. Master in Law. Research Professor at the Universidad Privada San Juan Bautista and professor at the Law School of the Universidad Nacional Mayor de San Marcos. RENACYT Code PO140233, http://orcid.org/0000-0003-1576-9464

PhD in Human Rights, Democracy and International Justice from the Universidad de Valencia. Master in Human Rights, Democracy and International Justice from the same university. Lawyer at the Universidad Católica de Colombia. Email: pasierra@ucatolica.edu.co https://orcid.org/0000-0002-3146-7418

Received: June 6, 2020; evaluated: March 8, 2021; accepted: April 8, 2021 


\title{
A INCIDÊNCIA DO NARCOTRÁFICO NAS ALTAS ESFERAS DE GOVERNO PERUANO
}

\author{
Manuel Bermúdez-T aPia \\ Universidad Privada San Juan Bautista \\ Paola Alexandra Sierra-Zamora \\ Universidad Católica de Colombia
}

\section{Resumo}

Desde meados dos anos 1980 até a atualidade, o narcotráfico vem tendo um grave impacto econômico, político e social no Peru. Em 2018, produto de uma pesquisa policial-fiscal, foi descoberta a relação entre uma quadrilha de narcotraficantes com alguns funcionários do poder judicial, do Ministério Público e do Conselho Nacional da Magistratura, os quais tinham vínculos próximos com as demais entidades do Estado, o que confirmou a presença de tais agentes nas altas esferas do poder. As consequências vêm enfraquecendo a democracia no país, porque as influências do narcotráfico podiam relacionar-se com membros do Congresso da República e inclusive do governo nacional. Portanto, o Estado executou ações normativas e institucionais para limitar a influência do narcotráfico e modificou a legislação penal-civil que regulamenta o controle financeiro e bancário, e a disposição de bens imóveis ligados a caso de lavagem de dinheiro; desativou o Conselho Nacional da Magistratura e destituiu a maioria dos funcionários de altas corporações judiciais do país.

Palavras-chave: Estado, administração pública, governabilidade, política, legislação e economia, serviço de justiça, poder judicial, Conselho Nacional da Magistratura, narcotráfico, lavagem de ativos, criminalidade organizada. 
Os autores: advogado formado com menção de Summa Cumme Laude pela Pontificia Universidad Católica del Perú. Mestre em Direito. Professor pesquisador da Universidad Privada San Juan Bautista e professor da Faculdade de Direito da Universidad Nacional Mayor de San Marcos. Código RENACYT PO140233, http://orcid.org/0000-0003-1576-9464 .

PhD Internacional em Direitos Humanos, Democracia e Justiça Internacional pela Universitat de Valéncia. Mestre em Direitos Humanos, Democracia e Justiça Internacional pela mesma instituição. Advogada pela Universidad Católica de Colombia. Correio eletrônico: pasierra@ucatolica.edu.co, https://orcid.org/0000-0002-3146-7418

Recebido: 6 de junho de 2020; avaliado: 8 de março de 2021; aceito: 8 de abril de 2021. 


\section{Introducción}

El modo tradicional de evaluar e identificar a la criminalidad organizada vinculada al narcotráfico había mostrado dos esferas de acción, cada una con sus particularidades: una, dedicada a la ejecución de actividades propias de producción, transporte, comercialización y distribución de drogas en el mercado y, la otra, a acciones de respaldo legal o económico, complementación y "lavado" de los beneficios económicos que genera el ilícito. ${ }^{1}$

Se observan dos tipos de personas en el ámbito de la comisión de un mismo delito, pero interactúan de modo indirecto, a efectos de ocultar alguna relación y evitar consecuencias judiciales o personales. Sin embargo, entre estos dos grupos existe un común denominador, relativo a la necesidad de salvaguardar los beneficios que procura la actividad delictiva.

Esta situación ha mutado en la gran mayoría de países, ${ }^{2}$ porque las personas que promueven los actos del narcotráfico en los escenarios urbanos, como el lavado de activos y la diversificación de las actividades económicas formales derivadas de una actividad ilícita, requieren ampliar sus redes de influencias para así garantizar un mejor método de protección de sus intereses o de la defensa de sus acciones en el campo judicial o político, si corresponde.

La doctrina ha logrado identificar este método de vinculación, que procura estar próximo a funcionarios o autoridades que dirigen alguna entidad del Estado, de preferencia derivados de elección popular, conforme se puede detallar en el Perú, en el caso de las regiones o municipalidades. ${ }^{3}$ Leonardo Raffo y Diego Gómez también han hallado en el estudio comparado las "redes de criminalidad" entre el narcotráfico y las autoridades gubernamentales. ${ }^{4}$

Estas referencias criminológicas en el Perú permitieron deducir una relación entre el narcotráfico y la gran mayoría de autoridades dedicadas a gestión pública en el

\footnotetext{
Adalberto Santana Hernández, El narcotráfico en América Latina (Ciudad de México: Siglo XXI, 2004), 11.

2 Juan Gabriel Tokatlián, Globalización, narcotráfico y violencia: siete ensayos sobre Colombia (Bogotá: Grupo Editorial Norma, 2000), 62.

3 Sandy Melgar, "La red de la bestia: la construcción de redes de corrupción en los gobiernos subnacionales, el caso de César Álvarez en Áncash", Revista de Ciencia Política y Gobierno 4, núm. 8 (2017): 139, https:// doi.org/10.18800/rcpg.201702.006

4 Leonardo Raffo y Diego Gómez Calderón, "Redes criminales y corrupción en la era del microtráfico y el narcomenudeo", Revista de Economía Institucional 19, núm. 37 (julio-diciembre 2017): 228, https://papers. ssrn.com/sol3/papers.cfm?abstract_id=3114208
} 
país, en todos los ámbitos de la Administración. Las evidencias provenían de varios elementos, como la publicación de resoluciones judiciales cuestionables respecto a la evaluación de expedientes judiciales de casos de lavado de activos, por ejemplo, o el financiamiento de partidos políticos en los procesos electorales, ${ }^{5}$ inclusive de numerosos congresistas en varios períodos legislativos. ${ }^{6}$

Inicialmente, esta situación no podía ser acreditada con elementos probatorios objetivos, por lo que muchas organizaciones vinculadas al narcotráfico podrían participar en las actividades del Estado, en especial de provisión y suministro de bienes y servicios mediante empresas constituidas para tal efecto, porque así no se cuestionaría la legalidad de los fondos económicos que se ingresaban al sistema financiero nacional.

El punto de quiebre surgió a raíz del descubrimiento de las acciones de la organización Los cuellos blancos del puerto, integrada por miembros del Poder Judicial, del Ministerio Público y del Consejo Nacional de la Magistratura, que se vinculaban con grupos empresariales y del hampa. ${ }^{7}$ Las relaciones se establecían por "contactos indirectos", para así limitar cualquier condición que provocara alguna investigación o sospecha sobre los funcionarios que ocupaban altos cargos en el Estado. ${ }^{8}$ Sin embargo, este contexto no era exclusivo del ámbito judicial, porque ya en los últimos períodos presidenciales y legislativos se tenía evidencia de una relación muy próxima entre el narcotráfico y autoridades políticas. ${ }^{9}$ Inclusive se habían identificado congresistas de la República con tales vínculos, por ejemplo:

a. El excongresista José León con el narcotraficante mexicano Rodrigo León y el excongresista Josué Gutiérrez con el narcotráfico de Huánuco, en la selva central peruana. ${ }^{10}$

5 Luis Pásara, Perú ante los desafíos del siglo XXI (Lima: Pontificia Universidad Católica del Perú, 2011), 12.

6 Perú 21, "Jaime Antezana: 'hay 14 congresistas vinculados al narcotráfico", Perú 21, Sec. Política, 5 de septiembre de 2014, https://peru21.pe/politica/jaime-antezana-hay-14-congresistas-vinculados-narcotrafico-183732-noticia/

7 Antonio Maldonado Paredes, "Un falso dilema en la lucha contra los delitos de cuello blanco", Testimonio, núm. 125 (2018): 8.

$8 \quad$ Isaac Beltrán y Eduardo Salcedo-Albarán, "Entornos generosos para el crimen: análisis del narcotráfico en Colombia", Borradores de Método, núm. 49 (agosto 2007): 2, https://www.researchgate.net/ publication/4829585_Entornos_generosos_para_el_crimen_Analisis_del_narcotrafico_en_Colombia

9 Jaime García y Gabriela Stöckli, El rol de las instituciones del Estado en la lucha contra las drogas en los países productores de hoja de coca (Lima: Instituto de Estudios Internacionales, 2014), 37.

10 Perú 21, "Jaime Antezana". 
b. El excongresista Edwin Vergara, a quien se le desaforó luego de un proceso penal por narcotráfico, al aprobarse una acusación constitucional en 2018. ${ }^{11}$

En estas circunstancias consideramos necesario evaluar la incidencia que ha tenido el narcotráfico en las altas esferas del Gobierno peruano e identificar cuáles han sido los actos que han impactado negativamente en el Estado. ${ }^{12}$

Se plantea, como objetivo del presente texto, demostrar que el descrédito, el déficit en la gestión pública y el debilitamiento de la institucionalidad democrática y de la legitimidad de las instituciones del Estado se deben a una acción planificada por las organizaciones vinculadas al narcotráfico, las cuales han contado con cómplices en el mismo Estado. ${ }^{13}$

En tal sentido, el descrédito que han tenido el Poder Judicial, el Ministerio Público, el Consejo Nacional de la Magistratura, el Congreso de la República y el Gobierno nacional ha sido tan elevado que provocó, en el año 2019, una reforma constitucional que implicó el cese de funciones del Consejo Nacional de la Magistratura y su reemplazo por la Junta Nacional de Justicia, tras destituir a todos sus integrantes.

Acto seguido, el Congreso de la República fue disuelto por el presidente Martín Vizcarra el 30 de septiembre del 2019. ${ }^{14}$ Entre los argumentos que justificaron dicha decisión se identificó la labor de algunos congresistas en la defensa de personajes con muestras claras de estar vinculados a mafias:

a. La defensa del exfiscal de la Nación, Pedro Chávarry, por parte de la bancada del fujimorismo, en especial porque este evitaba la investigación fiscal contra la lideresa de dicha agrupación, Keiko Fujimori. ${ }^{15}$

11 Canal N, "Edwin Vergara: Fuerza Popular suspendió militancia de congresista vinculado a narco", Canal N, Sec. Actualidad, 11 de abril de 2018, https://canaln.pe/actualidad/ edwin-vergara-fuerza-popular-suspendio-militancia-congresista-vinculado-narco-n317769

12 Gabriela Stöckli, "Narcotráfico en el Perú: ¿lucha contextualizada o contexto en lucha?", La Colmena, núm. 7 (2014): 8, http://revistas.pucp.edu.pe/index.php/lacolmena/article/view/12509

13 Hernán Manrique-López, "Política de drogas y narcotráfico en el Perú: del triunfalismo peruano al laberinto de la cocaína", Cultura y Droga 20, núm. 22 (2015): 64, http://vip.ucaldas.edu.co/culturaydroga/downloads/ Culturaydroga20(22)_04.pdf

14 Manuel Bermúdez-Tapia, "El control político del congreso del Perú a las acciones del Ejecutivo en estados de emergencia en ocasión a una pandemia", Opinión Jurídica 19, núm. 40 (2020): 341, https://doi.org/10.22395/ ojum.v19n40al7

15 Redacción, "Fujimorismo activa denuncias por encubrimiento contra Pedro Chávarry", Gestión, Sec. Política, 6 octubre 2019, https://gestion.pe/peru/politica/fujimorismo-archiva-denuncias -encubrimiento-pedro-chavarry-269731-noticia/ 
b. La defensa de César Hinostroza Pariachi, exjuez de la Corte Suprema, por parte de la bancada parlamentaria del fujimorismo, ante la acusación de ser parte de Los cuellos blancos del puerto. ${ }^{16}$

En este punto, las referencias dan cuenta de la defensa de congresistas de la bancada del fujimorismo por magistrados que conformaban la red de Los cuellos blancos del puerto, que fueron destituidos de sus cargos con una sanción político-penal en el Congreso de la República, con base en el Artículo 100 de la Constitución de 1993. ${ }^{17}$ Tal situación provocó el respaldo popular a la medida de disolución del Congreso de la República. ${ }^{18}$

Planteamos una hipótesis de trabajo que acreditará la relación entre el narcotráfico y la gestión pública nacional y se expondrán los casos más referenciales, muchos de los cuales aún se están juzgando e investigando en el ámbito judicial, porque se trata de una situación muy próxima.

Por último, con un enfoque metodológico, se evaluará la incidencia del narcotráfico en los tres poderes del Estado, para identificar su impacto negativo y la amplificación de la corrupción en el Perú. ${ }^{19}$

\section{El narcotráfico en el Perú: una visión general}

Alfonso Quiroz, en Historia de la corrupción en el Perú, ${ }^{20}$ narraba que los actos de corrupción han estado presentes en la mayor parte de la historia republicana del Perú y que esta fue la prolongación de lo que ocurrió durante la época colonial, ${ }^{21}$

16 La Mula, "Los 18 fujimoristas que blindaron a Hinostroza de la acusación criminal por 'Los cuellos blancos", La Mula, Sec. Redacción, 28 de septiembre de 2018, https://redaccion.lamula.pe/2018/09/28/ los-18-fujimoristas-que-blindaron-a-hinostroza-de-la-acusacion-criminal-por-los-cuellos-blancos/ redaccionmulera/

17 Manuel Bermúdez-Tapia, "El procedimiento parlamentario para nombrar altos funcionarios públicos en el Perú", Estudios Constitucionales 5, núm. 2 (2007): 275, https://www.redalyc.org/pdf/820/82050213.pdf

18 Andina Agencia Peruana de Noticias, "Encuesta IEP: 84\% de la población apoya disolución del Congreso", Andina, Sec. Política, 6 octubre 2019, https://andina.pe/agencia/noticia-encuesta-iep-84-de-poblacionapoya-disolucion-del-congreso-768815.aspx

19 Universidad Privada San Juan Bautista, "Análisis del impacto político, económico y social de la corrupción en la gestión pública. Proyecto de investigación desarrollado en la Facultad de Derecho de la Universidad Privada San Juan Bautista aprobado por Resolución de Vicerrectorado de Investigación No 017-2021-VRIUPSJB", https://investigacion.upsjb.edu.pe/docentes_investigacion/(acceso febrero 17, 2020).

20 Alfonso Quiroz, Historia de la corrupción en el Perú, 3a ed. (Lima: Instituto de Estudio Peruanos, 2019), 21.

21 Quiroz, Historia, 45. 
referencia que permite comprender el elevado grado de permeabilidad ante situaciones de corrupción en la psiquis social peruana.. ${ }^{22}$

Sin embargo, esta condición representativa de la historia republicana del Perú será delimitada para analizar el período que va desde los años ochenta del siglo pasado hasta el año 2019, con base en estos elementos:

a) El proceso de reformulación de las políticas nacionales de seguridad y defensa nacional respecto a la ampliación de los cultivos de coca, cuyo insumo posibilitaba la producción del clorhidrato de cocaína, ${ }^{23}$ y el desarrollo de actividades de producción, comercialización y movilización de estupefacientes al extranjero, en una cadena productiva que incidía en la economía y la realidad nacional.

Los cultivos de coca, usualmente distribuidos en zonas geográficas con población campesina y nativa en las regiones de selva alta en el Perú, ya no eran una referencia significativa, porque se registraban cultivos de coca en espacios donde no había presencia de comunidades originarias o campesinas, como en las regiones de San Martín, Ayacucho, Junín, Huánuco, Cerro de Pasco, Puno y Madre de Dios; ${ }^{24}$ ello muestra una característica étnica de los agricultores (colonos o mestizos) y una referencia comercial, por cuanto la producción no estaba sujeta a los parámetros de comercialización emitidos por la Empresa Nacional de la Coca (Enaco), ${ }^{25}$ dado que la producción superaba los requerimientos del mercado local para el chacchado de coca, que es una práctica ancestral consistente en masticar las hojas de coca. ${ }^{26}$

En este punto surgió una primera condición que provocó contradicciones en las políticas públicas peruanas de erradicación de cultivos ilícitos. El Estado permitía la producción de hoja de coca bajo la dirección de una entidad pública, pero, a la misma vez, analizaba con detenimiento el crecimiento de zonas de cultivo y

22 Manuel Bermúdez-Tapia, "Public Policies, Pandemic and Corruption: The 'Vacunagate' Case in Peru", Direitos Sociais e Politicas Públicas (Unifafibe) 9, núm. 1 (2021): 948, https://www.unifafibe.com.br/revista/ index.php/direitos-sociais-politicas-pub/article/view/1019

23 Nicolás Zevallos Trigoso, Control y defensa del cultivo de hoja de coca en el Perú (Lima: Pontificia Universidad Católica del Perú, 2016), 21.

24 Comisión de la Verdad y Reconciliación, Informe final (Lima: CVR, 2003), 740.

25 Nicolás Zevallos Trigoso, "Dinámicas locales en torno al cultivo de hoja de coca: elementos para el estudio desde el mercado ilegal de la cocaína", Revista de Ciencia Politica y Gobierno 4, núm. 7 (2017): 9, http:// revistas.pucp.edu.pe/index.php/cienciapolitica/article/view/19299

26 Fernando Rospigliosi, Cecilia Blondet y José Antonio Lloréns Amico, El consumo tradicional de la hoja de coca en el Perú (Lima: Instituto de Estudios Peruanos, 2004), 34. 
producción en zonas ajenas al contexto sociocultural andino, los cuales tenían como destino final la elaboración de estupefacientes.

A modo de referencia sociocultural, cabe aclarar que las comunidades indígenas amazónicas no consumen ni practican el chacchado de la hoja de coca por cuanto emplean otros insumos vegetales para la ejecución de sus actos cotidianos o prácticas costumbristas que requieren alucinógenos. ${ }^{27}$

Complementariamente, es importante examinar la vinculación de la ampliación de las zonas de cultivos ilícitos, la acción del Estado y la presencia de comunidades campesinas y nativas frente al consumo de la hoja de coca:

a. El registro de zonas de cultivos ilícitos en el país tiene tres etapas significativas: en la primera se ubican nuevas áreas de cultivo y cosecha en zonas geográficas donde no había población campesina o nativa; en la segunda se observa una acción formal del Estado peruano que busca su control y erradicación; en la tercera se efectúa el "cambio" de cultivos ilícitos por la agroindustria, que ha brindado notables éxitos económicos a las familias que se dedicaban a la producción de hoja de coca en regiones como Cajamarca, San Martín, Huánuco y Junín.

Esta tercera etapa fue denominada el "milagro san Martín" y propició el desarrollo alternativo agrícola en el Perú, porque se promovió un masivo programa de agroexportación, a cargo de la Comisión nacional para el desarrollo y vida sin drogas (Devida). ${ }^{28}$

De conformidad con el objetivo del presente texto, no se elabora un análisis cuantitativo de las zonas de cultivo de hoja de coca ni de las situaciones derivadas de la producción de cocaína, porque la investigación se centra en examinar cómo esta actividad ilícita se vincula con el Estado peruano.

b. En las regiones donde se ha presentado el cambio de cultivos, la población tiene origen mestizo y no consume la hoja de coca para el chacchado (masticado), factor determinante para que el Estado, por medio de Conaco, cuestionara, desde los años ochenta del siglo pasado, el cultivo y la producción de tales

27 Beatriz Caiuby y Henrik Jungaberle, eds., "The Internationalization of Ayahuasca" (Berlín: Global, 2011), 23.

28 Hugo Cabieses, "El 'milagro de San Martín' y los síndromes del 'desarrollo alternativo' en el Perú", Informes sobre politicas de drogas Transnational Institute, núm. 34 (2010): 4, https://www.tni.org/files/download/brief34s. pdf 
hojas en zonas ajenas al Cusco o a Puno, lugares de práctica tradicional masiva del chacchado.

c. La mayor parte de la cosecha de hoja de coca en zonas donde no había una población étnica que representara un mercado o compradores no tenía un registro de ventas o de destino final de la producción; allí se observó el incremento de campos de aterrizaje de avionetas con destino a Colombia para la producción de pasta básica de cocaína. ${ }^{29}$

De este modo, las iniciales políticas peruanas de control de cultivo, producción y comercialización de la hoja de coca fueron contradictorias, porque en principio se ejecutaron acciones que solo enfatizaban el control de zonas de cultivos sin tomar en cuenta el contexto sociocultural y económico de las áreas en las cuales esta actividad ya se había convertido en el principal elemento de desarrollo.

a. Entre los años 1980 y 2000, el terrorismo en el Perú se desarrolla y se amplifica por todo el territorio nacional, lo que provocó la militarización de la mayor parte de las zonas altoandinas y andinas vinculadas a la comercialización de hoja de coca, porque los grupos terroristas utilizaban tales condiciones geográficas como refugio. ${ }^{30}$

Como consecuencia, las propias comunidades campesinas y nativas optaron por un proceso de autodefensa, que es apoyado por el gobierno de Alberto Fujimori, e instituyeron las rondas campesinas y las rondas nativas, con acciones decididas contra el terrorismo y el narcotráfico, que se unificaron para acceder a beneficios compartidos. De este modo, las rondas reemplazaron al Estado, que no tenía presencia en las zonas donde había terrorismo o cultivos ilícitos. ${ }^{31}$

b. Debido a las acciones de las rondas, tanto Sendero Luminoso como el Movimiento Revolucionario Túpac Amaru (MRTA) establecieron alianzas con productores y comercializadores vinculados al narcotráfico y se dividieron los escenarios

29 Javier Bueno Victoriano, "Interdicción contra el transporte aéreo clandestino de derivados cocaínicos desde los departamentos de la Amazonía peruana hacia el extranjero en el período comprendido entre los años 2012 al 2014" (Tesis de Maestría, Pontificia Universidad Católica del Perú, 2016), 6.

30 Ricardo Soberón Garrido, "Distorsiones y prejuicios sobre narcotráfico y terrorismo: la selva alta y el Estado", Quehacer, núm. 181 (enero 2011): 38, https://go.gale.com/ps/anonymous?id=GALE\%7CA254260894\&si $\mathrm{d}=$ googleScholar\&v=2.1\&it=r\&linkaccess=abs\&rissn=02509806\&p=IFME\&sw=w

31 Oscar Espinosa, Rondas campesinas y nativas en la Amazonía peruana (Lima: Centro amazónico de antropología y aplicación práctica, 1995), 162. 
de operación: Sendero Luminoso se desarrollaría en el sur del Perú y el MRTA, en la zona noreste del país y en Lima. ${ }^{32}$

En la actualidad, existe una relación directa entre las últimas zonas en las cuales hubo presencia de grupos terroristas en el Perú y las zonas denominadas de "cultivos ilícitos", 33 como ocurre en el valle de los ríos Apurímac, Ene y Mantaro, en los departamentos de Ayacucho, Apurímac y Cusco. ${ }^{34}$

c. Surgen las primeras organizaciones de narcotraficantes en América Latina, que emplean redes internacionales de movilización de personas y pasta básica de cocaína desde Perú y Bolivia hacia Colombia, México y Estados Unidos. ${ }^{35}$ La organización de narcotraficantes más conocida en ese momento era el Cartel de Medellín y sus relaciones con productores, transportadores y política local aún no ha sido investigada a profundidad. ${ }^{36}$

d. Inicia la inserción del capital económico proveniente de actividades del narcotráfico al sistema financiero nacional mediante el "lavado de activos".

La legislación de regulación, control y punición del narcotráfico comienza a desarrollarse en forma exponencial. ${ }^{37}$

Con estos patrones de referencia se evidencia una relación histórica entre el narcotráfico y la Administración pública nacional, en la cual es posible observar:

a. En la primera época de la democracia civil (1980-1992).

32 Pablo Dreyfus, "Sendero luminoso: ¿un caso de narcoterrorismo", Revista de la Sociedad Argentina de Análisis Político 5, núm. 8 (1998): 3, https://revista.saap.org.ar/contenido/boletin-1999-otono/ot-dreyfus.pdf

33 Carlos Basombrío Iglesias y Fernando Rospigliosi, La seguridad y sus instituciones en el Perú a inicios del siglo XXI: reformas democráticas o neomilitarismo (Lima: Instituto de Estudios Peruanos, 2006), 137.

34 Adolfo Núnez, "El narcotráfico en el Perú: estrategias conjuntas de las fuerzas armadas y la Policía Nacional para su erradicación", Boletín de Información, núm. 260 (1999): 79, https://dialnet.unirioja.es/servlet/ articulo? codigo $=4626338$

35 Rubén Sánchez et al., Seguridades en construcción en América latina, Tomo I: El círculo de Colombia, Brasil, Ecuador, Panamá, Perú y Venezuela (Bogotá: Universidad del Rosario, 2005), 182

36 Martín Tanaka, La situación de la democracia en Colombia, Perú y Venezuela a inicios de siglo (Lima: Comisión Andina de Juristas, 2002), 45.

37 Dino Carlos Caro Coria y Luis Reyna Alfaro, Compliance y prevención del lavado de activos y del financiamiento del terrorismo: actas del I Foro internacional de compliance y prevención del lavado de activos y del financiamiento del terrorismo (Lima: Centro de Estudios de Derecho Penal Económico y de la Empresa, 2013), 14. 
i. Las organizaciones y los partidos políticos no tenían un vínculo directo o público con grupos o personajes asociados al ámbito del narcotráfico, pese a algunos elementos que permitían acreditar el lazo, como había sucedido con Víctor Raúl Haya de la Torre, por ejemplo. ${ }^{38}$

Una referencia mucho más notoria es el caso de Carlos Lamberg Meléndez, quien había financiado la campaña política presidencial del APRA en 1980 y que en 1984 fue sentenciado por narcotráfico. ${ }^{39}$

ii. Durante el gobierno de Fernando Belaúnde Terry se promulgó el Decreto Ley 22927 (4/03/1980), que establecía la prohibición de la compra de coca por parte de la Empresa Nacional de la Coca a partir de 1981, con lo cual se originó una crisis social, porque mucha población campesina y nativa no pudo obtener hojas para sus prácticas tradicionales y acudió a un mercado informal e ilegal que derivaba parte de la producción cultivada de zonas de montaña a zonas andinas. ${ }^{40}$

Si bien dicha medida apuntaba a controlar el aumento de las hectáreas dedicadas a cultivos ilícitos, tuvo un efecto contrario, porque se amplió tanto el volumen de toneladas de cosecha como de zonas de producción, pues las poblaciones vinculadas a la actividad se desplazaron a territorios donde no había un control policial. Así inició la masificación de los cultivos ilícitos en el país y una relación muy estrecha con Sendero Luminoso. ${ }^{41}$

En este caso, el grado de incidencia negativo que provocaría el narcotráfico fue negligentemente evaluado por el Gobierno nacional.

iii. Durante el primer gobierno de Alan García (1985-1990), el Movimiento Revolucionario Túpac Amaru (MRTA) se ligó al narcotráfico, al compartir la misma zona de incidencia geográfica: los departamentos de San Martín y

38 José Carlos Ugaz Sánchez Moreno, Prensa juzgada: treinta años de juicios a periodistas peruanos (1966-1999) (Lima: Pontificia Universidad Católica del Perú, 1999), 37.

39 Reynaldo Ramírez, Los jueces de Montesinos: la red montesinita en el poder judicial 1990-2000 (Lima: Academia de Magísteres y Doctores del Perú, 2002), 73.

40 Rodrigues Montoya Rojas, "El Perú después de 15 años de violencia", Estudos Avançados 11, núm. 29 (1997): 287, https://www.researchgate.net/publication/250982679_El_Peru_despues_de_15_anos_de_violencia_1980-1995

41 Santana Hernández, El narcotráfico, 206. 
Ucayali. ${ }^{42}$ Desde allí organizó su actividad terrorista y de comercialización a gran escala de pasta básica de cocaína destinada a la exportación. ${ }^{43}$

El APRA no había ejecutado ninguna acción eficiente para controlar el narcotráfico y tampoco al MRTA, en especial en Lima, donde cometió los siguientes actos:

i. El secuestro de empresarios y personajes públicos entre los años 1984 y 1996. El caso más conocido es el de Héctor Delgado Parker en 1989. ${ }^{44}$

ii. La toma frustrada del Congreso de la República por parte de Peter Cárdenas Shulte. ${ }^{45}$

iii. La huida del Centro Penitenciario Castro Castro de los altos dirigentes del MRTA en 1990. ${ }^{46}$

La población peruana asumió estos hechos como parte de la relación entre el APRA y el MRTA,${ }^{47}$ a causa de los antecedentes entre Alan García y Víctor Polay, líder del MRTA, quienes habían compartido vivienda mientras cursaban estudios de posgrado en Madrid y en París en la década del setenta del siglo pasado. ${ }^{48}$

b. Durante el gobierno de Alberto Fujimori (1992-2001).

En este período se presentaron los siguientes hechos, que permiten suponer que hubo cercanía entre el presidente de la República y el narcotráfico:

42 Comisión de la Verdad y Reconciliación, Informe, 738.

43 Julio Cotler, ¿Nuevos horizontes para el Perú? Nueva sociedad, núm. 80 (noviembre-diciembre 1985): 115, https://nuso.org/articulo/nuevos-horizontes-para-el-peru/

44 Diario Correo, "Los secuestros del MRTA", Diario Correo, Sec. Lima, 29 septiembre 2015, https://diariocorreo. pe/opinion/los-secuestros-del-mrta-621455/

45 Gerardo Saravia y Patricia Wiesse, "Un hueso duro de roer", Ideele, núm. 255 (2013), https://revistaideele. com/ideele/content/un-hueso-duro-de-roer

46 Carlos Batalla, "El túnel de Polay: la fuga del terrorista que causó estupor en los peruanos en 1990", El Comercio, Sec. Archivo, 7 diciembre 2020, https://elcomercio.pe/archivo-elcomercio/ victor-polay-tunel-fuga-penal-castro-castro-1990-nnsp-noticia/

47 Nicolás Lynch, Una tragedia sin héroes: la derrota de los partidos y el origen de los independientes, Perú 1980-1992 (Lima: Universidad Nacional Mayor de San Marcos, 1999), 230.

48 Jonathan Castro, "Alan García a excabecilla del MRTA, Víctor Polay: date por bien pagado", La República, Sec. Política, 31 julio 2011, https://larepublica.pe/politica/561161-alan-garcia-a-ex-cabecilla-del-mrta -victor-polay-date-por-bien-pagado/ 
i. La captura de una carga de pasta básica de cocaína en el avión presidencial, que estaba a punto de dar un vuelo secreto, sin tener el permiso de salida de las autoridades aeroportuarias ni el registro de embarque, aparte de la "autorización" del entonces presidente Alberto Fujimori.

El 11 de mayo de 1996, un cargamento de 170 kilos de cocaína fue localizado en el avión de la Fuerza Aérea Peruana (FAP), de clase y matrícula DC8-62F N. ${ }^{\circ}$ 371, que tenía previsto desarrollar un "vuelo secreto" rumbo a Rusia para "llevar motores y equipos bélicos necesitados de mantenimiento". 49

Pese a las circunstancias, la tripulación no fue condenada por el delito de tráfico ilícito de droga, como tampoco fue procesado o investigado algún funcionario de alto rango de las Fuerzas Armadas peruanas, del Ministerio de Guerra o del Gobierno nacional. Alberto Fujimori, en 1997, pronunció un discurso público en el cual exculpó de responsabilidad a la tripulación, en particular a su edecán, el comandante FAP Luis Escarcena Ishikawa, conforme expone la investigación que adelantó el Congreso de la República en su momento. ${ }^{50}$

En 1997 en un discurso público, Alberto Fujimori exculpó al comandante FAP Luis Escarcena Ishikawa (piloto de la aeronave) de toda responsabilidad penal en el "narcoavión" y, por eso, los órganos judiciales de la época lo citaron solo como "testigo" en las investigaciones. ${ }^{51}$

ii. El control, por parte de Vladimiro Montesinos y Alberto Fujimori, de vuelos ilícitos dirigidos por el narcotráfico.

Uno de los principales narcotraficantes de la década de los años noventa del siglo pasado, Demetrio Limonier Chávez Peñaherrera, el Vaticano, tras ser capturado por la Policía Nacional dio varias entrevistas a la prensa y comentó que Vladimiro Montesinos y Alberto Fujimori eran quienes controlaban los vuelos ilícitos de las zonas de producción cocalera hacia el extranjero a cambio de un pago mensual de

49 Manuel Dammert, Fujimori-Montesinos: El Estado mafioso. El poder imagocrático en las sociedades globalizadas (Lima: El Virrey, 2001), 201.

50 Perú, Congreso de la República, "Secretos del narcoavión", http://www2.congreso.gob.pe/Sicr/GrupParlamentarios/bloquepopular.nsf/vf12web/D404A9111EB44D58052578A70051A794/\$FILE/Secretos.pdf (acceso marzo 17, 2020).

51 Romina Mella, "Secretos del narcoavión", IDL-Reporteros, Sec. Exclusivo, 4 junio 2011, https://www. idl-reporteros.pe/secretos-del-narcoavion/ 
US \$ 50000 entre 1991 y $1992 .{ }^{52}$ Pese a estas imputaciones, no hubo investigación fiscal o por el Congreso de la República. ${ }^{53}$

Inclusive, la sentencia a treinta años de cárcel para Chávez Peñaherrera no hace referencia significativa a las condiciones políticas y logísticas que favorecían su actividad de traslado y comercialización de drogas entre Perú y Colombia, aunque era uno de los elementos más importantes del proceso judicial. ${ }^{54}$

iii. La venta de armas a las FARC-EP. En el año 2006, Vladimiro Montesinos fue condenado por haber cometido delitos contra la Administración pública y de contrabando, al suministrar fusiles Ak-47 a las Fuerzas Armadas Revolucionarias de Colombia Ejército del Pueblo (FARC-EP). ${ }^{55}$

Con los elementos evaluados en el proceso judicial se acreditó que el financiamiento para el pago por el contrabando provenía del narcotráfico y del tesoro público, con lo cual se demostraba la participación de las altas esferas del poder en actividades propias del narcotráfico.

A pesar de las circunstancias, Alberto Fujimori no fue involucrado en el proceso, pese a tener una relación sumamente estrecha con su agente y con todas sus actividades en el Gobierno nacional, calificado como un "narcoestado" por los mismos narcotraficantes. ${ }^{56}$

c. En la segunda época de la democracia civil (2001 a 2020) se registraron los siguientes hechos, que muestran una serie de vínculos formales y notorios entre personajes ligados al narcotráfico y altas autoridades de algunas entidades:

52 Jane Marcus-Delgado y Martín Tanaka, Lecciones del final del fujimorismo: la legitimidad presidencial y la acción política (Lima: Instituto de Estudios Peruanos, 2001), 48.

53 Coletta Youngers y Eileen Rosin, Drogas y democracia en América Latina: el impacto de la política de Estados Unidos (Buenos Aires: Biblos, 2005), 266.

54 Iván Rodríguez Alegre, Vladimiro Montesinos y el poder politico en el mandato de Alberto Fujimori (Lima: San Marcos, 2007), 111.

55 Marcus-Delgado y Tanaka, Lecciones, 13.

56 Canal N, "Vaticano: "El Perú fue un narcoestado durante el gobierno de Fujimori", Canal N, Sec. Actualidad, 13 enero 2016, https://canaln.pe/actualidad/demetrio-chavez-penaherrera-vaticano-libertad-alberto-fujimori-n214798 
i. Durante el segundo Gobierno aprista (2006-2011), uno de los principales narcotraficantes peruanos declaró, en el momento de su captura, que su familia tenía relaciones con la cúpula del partido que gobernaba el país. ${ }^{57}$

En el Perú, la legislación sobre contratación pública exige requisitos financieros específicos a los proveedores del Estado. Sin embargo, con la captura de Gerald Oropeza se evidenció la flexibilización de esos requerimientos en la evaluación de sus empresas, previo acuerdo económico a favor de las autoridades de dichas entidades, quienes actuaban bajo dependencia de la cúpula del partido de Gobierno.

La relación entre el narcotraficante capturado y el partido político fue descubierta por la prensa luego de que se demostraran la asignación de bienes incautados a la corrupción a favor de Gerald Oropeza y la celebración de contratos con entidades por influencia del partido de Gobierno. ${ }^{58}$

ii. Los narcoindultos y el proceso de liberación de personas que "compraban" los beneficios penitenciarios dirigidos por la cúpula aprista entre los años 2006 y 2011.

Durante el segundo gobierno de Alan García Pérez se instituyó una política penitenciaria que permitía la excarcelación de presos con sentencias condenatorias, tendiente a lograr su reinserción social y a reducir el volumen de presos en las cárceles, ${ }^{59}$ con base en una coordinación "extraoficial" entre estas personas y agentes del Ministerio de Justicia bajo liderazgo del entonces ministro Aurelio Pastor, quien posteriormente fue juzgado y condenado por el delito de tráfico de influencias. ${ }^{60}$

Este proceso de "beneficios" otorgados a personas condenadas por delitos graves, conforme la legislación penal de entonces ocasionó: a) 70 indultos humanitarios a sentenciados por tráfico ilícito de drogas; b) 2 indultos a sentenciados por tráfico ilícito de drogas, y c) 3207 conmutaciones de pena (variación de carcelería por un

\footnotetext{
La República, "Gerald Oropeza y sus nexos con el APRA", La República, Sec. Política, 24 abril 2015, https:// larepublica.pe/politica/872094-gerald-oropeza-y-sus-nexos-con-el-apra-imagen-interactiva/?ref=lre 39cHdJA 58 Francisco Durand, "APRA y narcotráfico", Otra Mirada, Sec. Inicio, 29 abril 2015, bit.ly/3boTBYr

59 Pedro Cateriano Bellido, El caso García (Lima: Planeta, 2017), 23.

60 Fernando Tuesta Soldevilla, Perú: elecciones 2016. Un país dividido y un resultado inesperado (Lima: Pontificia Universidad Católica del Perú, 2017), 52.
} 
beneficio penitenciario) durante el período del 28 de julio de 2006 al 27 de julio de 2011, en el segundo gobierno de Alan García Pérez. ${ }^{61}$

iii. El lavado de activos con pago de servicios y actividades durante los procesos electorales.

A partir del año 2001, todos los procesos electorales registraron una participación política muy elevada de la ciudadanía. El presupuesto del que cada organización política disponía era muy superior a los datos que proporcionaba a las entidades electorales que fiscalizaban cada contienda. La legislación electoral peruana no había regulado hasta entonces el procedimiento de fiscalización, rendición de cuentas o control del secreto bancario de las organizaciones políticas; ante este vacío, todas las organizaciones políticas disponían libremente de sus fondos, en especial para: i) contratar candidatos a un cargo político, a efectos de asociar su imagen con la organización política; ii) financiar la campaña política de algún personaje con respaldo social, y iii) financiar actividades sociales. ${ }^{62}$

Ante estas condiciones, el Jurado Nacional de Elecciones propuso la reforma de la Ley de Partidos Políticos, Ley 28 094, y se definieron sanciones de carácter administrativo y penal a las organizaciones que no lograran acreditar el ingreso de fondos y su disposición en cada proceso electoral. Dicha regulación provocó que los partidos políticos asumieran un nuevo comportamiento para evitar el control o la fiscalización de sus cuentas bancarias y dio lugar a una acción que fue repetida por la mayoría de las organizaciones políticas: "dividir" los fondos provenientes de aportantes que no querían figurar en el padrón de financiamiento y registrar varias personas como "aportantes".

Este acto fue denominado "pitufeo" y es uno de los principales problemas del sistema político peruano, en particular porque la mayor parte de aportes no tiene un origen conocido o determinado por las mismas organizaciones políticas. ${ }^{63} \mathrm{Como}$ consecuencia de esta reforma legislativa, varios líderes de organizaciones políticas fueron investigados y procesados. ${ }^{64}$ Los casos de mayor impacto fueron:

${ }^{61}$ Perú, Congreso de la República, Comisión de Investigación de los narcoindultos en el Congreso de la República del Perú, "Comisión Montenegro" (Lima: Congreso de la República, 2016).

62 Tuesta Soldevilla, Perú, 36.

63 Grupo de Acción Financiera de Sudamérica, Informe de evaluación mutua anti lavado de activos y contra el financiamiento del terrorismo (3ra ronda) (Bogotá: Autor, 2008), 4.

64 Luz María Puente Aba, El delito de financiación ilegal de partidos políticos (Valencia: Tirant lo Blanch, 2017), 114. 
La detención y prisión preventiva por casi año y medio de Keiko Fujimori, quien no ha logrado demostrar la fuente que financió su campaña política en los años 2006 y 2011, puesto que los "aportantes" que figuraban en su padrón financiero tienen una condición de pobreza extrema.

La investigación y prisión preventiva a Ollanta Humala y Nadine Heredia, por no acreditar el modo de generación de fondos para la campaña política del año 2011. Se halló un desbalance patrimonial significativo que ha provocado que el expresidente continúe como "investigado" y su esposa sea procesada; al no tener prerrogativas constitucionales por haber ejercido una alta función en el Estado, se le impuso prisión preventiva por un año. En la actualidad, ambos personajes siguen procesados, al igual que Keiko Fujimori, pero el Ministerio Público ya ha formulado acusación penal y solicita la condena por acreditar hechos propios de actos de lavado de activos. ${ }^{65}$

\section{El narcotráfico y su vinculación con congresistas del Congreso de la República}

Paralelo a lo observado en los Gobiernos nacionales desde 1985 hasta 2021, en el Congreso de la República se han identificado tres casos en los que se ha acreditado la vinculación del narcotráfico con el poder político.

a. El descubrimiento del depósito de drogas en un almacén de propiedad de Kenji Fujimori. En 2013, la Policía Nacional del Perú ubicó un cargamento de 100 kilos de cocaína pura en un almacén ubicado en Callao. La empresa en el mencionado inmueble era de propiedad de dos personajes de la vida política nacional: Kenji Fujimori y Miguel Ángel Ramírez Huamán, quienes tenían participación en el partido político Fuerza 2011, liderado por Keiko Fujimori, ${ }^{66}$ por el cual Kenji Fujimori ya era congresista desde 2011.

65 Yvan Montoya, "La agonía de la lucha contra la corrupción en el Perú", Proyecto Anticorrupción 47, núm. 10 (noviembre 2015): 6, http://cdn01.pucp.education/idehpucp/wp-content/uploads/2017/07/01191226/2015_ boletin54.pdf

66 Manuel Vigo, "Kenji Fujimori, Most Popular Congressman. Linked to Drug Trade", Telesur, Sec. Latin America, 10 abril 2016, https://www.telesurenglish.net/news/Kenji-Fujimori-Most-Popular-CongressmanLinked-to-Drug-Trade-20160410-0039.html 
La relación del narcotráfico con el partido fujimorista no se limitó a este hecho ${ }^{67}$ porque también se ha observado:

- Personas vinculadas al narcotráfico se asociaban con las organizaciones políticas para participar como candidatas por un distrito electoral en la elección del Congreso de la República. Al conocer estos antecedentes, las organizaciones políticas podían obtener un financiamiento elevado que les permitiría desarrollar sus actividades. Esto fue comprobado cuando se evaluó el caso del congresista Edwin Vergara, al acreditarse el pago de cupos por su participación política en la lista parlamentaria del fujimorismo por medio de empresas vinculadas al narcotráfico.

- Joaquín Ramírez, secretario general del partido de Keiko Fujimori, fue acusado de lavado de activos y de ser parte de una organización de narcotraficantes. Logró "ganar" un caso en la Corte Suprema que le permitía "exigir" la acreditación del "delito fuente" en casos de investigación de lavado de activos. ${ }^{68}$

Esto es, la Corte Suprema exigía que cada caso relacionado con lavado de activos tuviera una condena previa por nexo con el narcotráfico, con lo cual la persecución y el procesamiento de la mayoría de los procesos judiciales en la especialidad quedaban anulados. El juez de la Corte Suprema que sustentó este fallo fue César Hinostroza Parichi, sindicado en los años siguientes como cabecilla de la organización Los cuellos blancos del puerto, que organizaba, junto con fiscales supremos en la Fiscalía de la Nación y el Consejo Nacional de la Magistratura, la manipulación de casos "importantes". ${ }^{6}$

b. Las congresistas cocaleras. Luego de haber sido congresistas de la República entre 2006 y 2011, Nancy Obregón y Elsa Malpartida volvieron a sus actividades habituales en la región San Martín, hasta que en 2017 fueron condenadas

${ }^{67}$ Jonathan Rosen y Hanna Samir Kassab, Fragile States in the Americas (Lanham: Lexington Books, 2017), 144.

68 Óscar Castilla, "Acusado de capo de la droga de Perú junto a financista de Keiko están en la mira de la DEA", Ojo público, Sec. Especiales, 17 mayo 2016, https://ojo-publico.com/222/ acusado-de-capo-de-la-droga-de-peru-junto-financista-de-keiko-estan-en-la-mira-de-la-dea

69 La República, "Los cuellos blancos del puerto: el origen del nombre de la organización criminal", La República, Sec. Política, 7 julio 2019, https://larepublica.pe/politica/2019/07/07/ los-cuellos-blancos-del-puerto-el-origen-del-nombre-de-la-organizacion-criminal/ 
a 35 y 23 años, respectivamente $e^{70}$ por participar en actividades propias del narcotráfico y financiar actividades terroristas. ${ }^{71}$

Las actividades a favor del narcotráfico y de acciones de terrorismo de estas dos exparlamentarias peruanas propiciaron, entre otras cosas, lo siguiente:

i. La "marcha de sacrificio", en la cual se procuraba "defender" la inocencia de Nelson Palomino, quien era el mayor dirigente cocalero que tenía vínculos estrechos con el narcotráfico. ${ }^{72}$ Pese a las evidencias, la mencionada marcha provocó la crisis de gobernabilidad de la administración de Alan García, ${ }^{73}$ en especial porque en otras localidades también existían otros conflictos sociales.

ii. La limitación de las actividades de erradicación de cultivos ilícitos en localidades como San Marín, Huánuco y Junín, porque las bases políticas de las exparlamentarias estaban en áreas, las cuales eran conocidas como parte de zonas de alto movimiento de pasta básica de cocaína hacia el extranjero. ${ }^{74}$

c. Los congresistas vinculados al narcotráfico de forma directa e indirecta. En el año 2018, Jaime Antezana, un reconocido especialista en temas de narcotráfico en el Perú, afirmó que había identificado a veintiún congresistas relacionados con el narcotráfico. ${ }^{75}$

La acreditación de personajes vinculados al narcotráfico que habían logrado ser elegidos congresistas de la República fue verificado en una sentencia penal contra el congresista Edwin Vergara. Ante la existencia de una condena penal por narcotráfico,

70 Perú al día, "Juicio oral para Nancy Obregón y Elsa Malpartida", Perú al día, Sec. Nacional, 21 septiembre 2017, https://www.perualdia.pe/juicio-oral-para-nancy-obregon-y-elsa-malpartida/

71 Agencia de Prensa Ambiental, "Pasado senderista de Elsa Malpartida 'engancha perfectamente' con su conocida "prédica violentista y radical", Inforegión, Sec. Seguridad, 4 noviembre 2009, https://www.inforegion.com.pe/40875/ pasado-senderista-de-elsa-malpartida-engancha-perfectamente-con-su-conocida-predica-violentista-y-radical/ comment-page-1/

72 Manuel Jesús Ojeda Acosta, "El proceso de transformación de la relación política entre el Partido Nacionalista Peruano y el movimiento cocalero de la zona del VRAE, durante la campaña electoral del 2011" (Tesis de Maestría, Pontificia Universidad Católica del Perú, 2012), 22.

73 Xavier Albó, Movimientos y poder indígena en Bolivia, Ecuador y Perú (La Paz: Cipca, 2008), 214.

74 MRT, "Cocaleros realizan 'marcha de sacrificio' en Pert", MRT, Sec. Noticias, 11 julio 2005, https://www. mrt.com/news/amp/Cocaleros-realizan-marcha-de-sacrificio-en-Pert-7699724.php

75 Wayka, "Existen 21 narco-congresistas según investigador Antezana", https://wayka.pe/existirian-al-menos21-narco-congresistas-segun-investigador-antezana/ (acceso mayo 12, 2020). 
el Congreso de la República propuso su desafuero como congresista mediante una acusación constitucional aprobada por la Comisión Permanente, conforme a lo establecido en la Constitución. ${ }^{76}$

Estos sucesos confirman el hecho de que las personas que ejecutan actividades vinculadas al narcotráfico, sea en forma directa como indirecta, tienen un grado de participación en la vida política nacional.

La fragilidad de la institucionalidad y de la legalidad de las organizaciones políticas en el Perú permiten la participación de caudillos políticos, quienes entablan alianzas con organizaciones vinculadas al narcotráfico y a la delincuencia para acceder a cargos públicos de elección democrática, como ocurrió con la elección de Edwin Vergara.

\section{La vinculación del narcotráfico con personajes del ámbito judicial}

En este contexto se presentan dos situaciones muy particulares, las cuales se complementan debido a que se relacionan con un mismo personaje.

a. El resultado de la casación sobre "Lavado de activos", N. . 92-2017, Arequipa (08/08/2017). Este fallo de la Corte Suprema dispuso una situación muy específica: el delito fuente era el elemento normativo del tipo objetivo de los tres subtipos normativos del Código Penal que regulaban el delito del lavado de activos, con lo que se emitía una interpretación judicial que condicionaba negativamente el Decreto Legislativo N. ${ }^{\circ} 1249$ (que había modificado el Decreto Legislativo $\mathrm{N}^{\circ}{ }^{\circ} 1106$ ) que regulaban el delito de lavado de activos y otros delitos ligados a la minería ilegal y al crimen organizado. ${ }^{77}$

Las críticas hacia el contenido de la Casación enfatizaban la necesidad de un "proceso previo" para demostrar un acto de lavado de activos, hecho que provocó que la misma Corte Suprema, por medio del Pleno Casatorio 01-2017, dejara sin

76 Perú, Congreso de la República, "Recomiendan destituir a tres congresistas", http://www.congreso.gob.pe/ index.php?K=263\&id=11173/noticias/RECOMIENDAN-DESTITUIR-A-TRES-CONGRESISTAS (acceso abril 25, 2020).

77 Ingrid Díaz, coord., Protocolo de actuación para periodistas en la investigación de casos de corrupción y lavado de activos (Lima: Pontificia Universidad Católica del Perú, 2017), 10. 
efecto el carácter vinculante que tenía el del 11 de octubre de 2017 y precisara los indicios del delito precedente en el delito de lavado de activos.

Téngase en cuenta que el tiempo entre la mencionada Casación y el Pleno Casatorio permitió cuestionar la primera decisión judicial, porque resultaba contraria a la lucha contra el narcotráfico, en particular en los actos de lavado de activos.

Por lo controversial del fallo inicial surgieron las suspicacias necesarias contra el juez César Hinostroza Pariachi, quien posteriormente fue identificado como el jefe de la organización criminal de Los cuellos blancos del puerto, ${ }^{78}$ conforme la acusación constitucional ante el Congreso de la República a cargo del fiscal supremo Pablo Sánchez Velarde, que fue desestimada por parte de la bancada fujimorista en 2018, en una manifiesta línea de apoyo del fujimorismo a sus aliados en el poder Judicial y el Ministerio Público.

La defensa de personajes cuestionados posibilitó observar:

i. El proceso judicial y un fallo cuestionable a favor de Joaquín Ramírez, financista del fujimorismo durante las campañas políticas de 2006 y 2011 , contrario a los medios probatorios actuados. ${ }^{79}$

ii. El apoyo a las acciones del fiscal de la nación, Pedro Chávarry, luego de sustraer documentos de una oficina que seguía las investigaciones contra el partido fujimorista. ${ }^{80}$

Ambos actos sucedieron en una etapa previa al descubrimiento de una red de corrupción en las altas esferas del Estado peruano.

b. La evidencia de los movimientos de Los cuellos blancos del puerto. En julio de 2018 se difundieron en los medios de comunicación unos audios acerca de cómo actuaban algunos magistrados y el Ministerio Público. Tales magistrados, en complicidad con miembros del Consejo Nacional de la Magistratura, integraban

78 La República, "Red 'Los cuellos blancos del puerto".

79 RPP, "Abogado de Joaquín Ramírez sostuvo reunión con César Hinostroza y Walter Ríos”, RPP Noticias, Sec. Redacción, 12 agosto 2018, https://rpp.pe/politica/actualidad/ abogado-de-joaquin-ramirez-sostuvo-reunion-con-cesar-hinostroza-y-walter-rios-noticia-1142833

80 Diego Pereira, "El fujimorismo blinda a Pedro Chávarry por sustraer documentos de oficinas lacradas", Útero, Sec. Curwen, 28 mayo 2019, http://utero.pe/2019/05/28/el-fujimorismo-blinda-a-pedro-chavarrypor-sustraer-documentos-de-oficinas-lacradas-pero-lo-peor-viene-despues/ 
una organización criminal que podía emitir resoluciones judiciales favorables a los "hermanos" que requerían dichos "servicios", como se afirmaba en los audios y que fue motivo para que la prensa nacional los identificara de esa manera. $^{81}$

Estos hechos fueron llamados "los CNM audios" y forman parte de una investigación que desarrolló el Ministerio Público en el distrito fiscal del Callao, en la que se logró descubrir el comportamiento negativo y ajeno a la ética profesional de magistrados que conformaban la organización denominada Los cuellos blancos del puerto. ${ }^{82}$

A raíz de la difusión de varios audios se detectó que César Hinostroza Pariachi, juez de la Corte Suprema, emitía resoluciones judiciales con un objeto distinto a lo que implicaba el ejercicio independiente, autónomo y razonado de la judicatura. Las evidencias fueron las siguientes:

i. El archivo del caso de Joaquín Ramírez por lavado de activos. ${ }^{83}$

ii. La evaluación del caso de Keiko Fujimori, que finalmente fue trasladado a otros jueces por la denuncia.

\section{El narcotráfico en la política nacional}

Debido a lo expuesto en los puntos precedentes, la relación entre el narcotráfico y las autoridades de la Administración pública peruana se gestaba a consecuencia del común intercambio de favores entre los partidos políticos y el narcotráfico, porque los primeros requerían financiar sus actividades y los segundos requerían "ingresar" sus ganancias económicas al sistema financiero nacional.

El uso de una gran cantidad de recursos económicos por parte de las organizaciones políticas en los procesos electorales mostró una alianza implícita con el narcotráfico,

81 Laura Zúñiga Rodríguez, "La captura del Estado peruano por el narcotráfico: el caso de los 'Cuello blanco del puerto". Revista de Estudios en Seguridad Internacional 6, núm. 2 (2020): 175-191.

82 Perú, Ministerio Público, Fiscalía de la Nación, "Fiscalía desarticula organización criminal 'Los cuellos blancos del puerto' en el Callao a partir de escuchas telefónicas legales, https:/www.gob.pe/institucion/ $\mathrm{mpfn/noticias/436488-fiscalia-desarticula-organizacion-criminal-los-cuellos-blancos-del-puerto-en-el-callao-}$ a-partir-de-escuchas-telefonicas-legales (acceso marzo 20, 2020).

83 Claudia Ortiz, "Decisión de juez Hinostroza permitió archivar caso de Joaquín Ramírez", La República, Sec. Política, 8 julio 2018, https://larepublica.pe/politica/1275185-cesar-hinostroza-permitio -archivar-caso-lavado-activos-joaquin-ramirez/ 
porque no había una relación proporcional entre la representatividad política generada por la elección y el presupuesto empleado en la campaña. ${ }^{84}$

La necesidad de establecer una red propició una relación casi complementaria entre las organizaciones políticas y el narcotráfico, conforme narra Carlos Meléndez, ${ }^{85}$ en particular con el fujimorismo, el APRA y las organizaciones independientes que precisaban fuentes de financiamiento a gran escala, factor que condujo a que este contexto se ampliara al poder Judicial, al Ministerio Público y al Consejo Nacional de la Magistratura.

Lo detallado no exonera de responsabilidad al elector peruano, que hace una deficiente evaluación de los candidatos que se postulan para un cargo en la gestión de Gobierno, en particular, de los factores propios de la estructura interna de una organización política (dirigencia, organización política, ideología, financiamiento) y, a pesar de las evidencias, no asume estas condiciones como un elemento negativo. ${ }^{86}$

\section{Conclusiones}

Conforme a lo analizado, las situaciones y los casos particulares presentados en las entidades que conforman la estructura central del Estado peruano —Gobierno nacional, Congreso de la República, poder Judicial, Ministerio Público y Consejo Nacional de la Magistratura- demuestran el efecto negativo del narcotráfico en las altas esferas de poder en el Perú.

El mecanismo que ha empleado el narcotráfico para incidir en las entidades públicas está vinculado a las debilidades de cada una de las instituciones públicas y de la falta de liderazgo y autonomía que sus autoridades han manifestado, por cuanto, ante las evidencias de vínculos manifiestos, no han expresado su rechazo.

El registro de congresistas ligados al narcotráfico, la actividad judicial para evitar juzgar diligentemente casos de lavados de activos y la evidencia en algunos casos en el Ejecutivo permiten observar que el narcotráfico está muy presente en el escenario nacional peruano.

84 Carlos Meléndez Guerrero, El mal menor: vínculos políticos en el Perú posterior al colapso del sistema de partidos (Lima: Instituto de Estudios Peruanos, 2019): 25.

85 Meléndez Guerrero, El mal, 72.

86 Cristóbal Aljovín de Losada y Sinesio López, eds., Historia de las elecciones en el Perú, 2a ed. (Lima: Instituto de Estudios Peruanos, 2018), 231. 


\section{Referencias}

Agencia de Prensa Ambiental. "Pasado senderista de Elsa Malpartida 'engancha perfectamente' con su conocida 'prédica violentista y radical”. Inforegión, Sec. Seguridad, 4 noviembre 2009, https://www.inforegion.com.pe/40875/pasado-senderista-de-elsamalpartida-engancha-perfectamente-con-su-conocida-predica-violentista-y-radical/ comment-page-1/

Albó, Xavier. Movimientos y poder indígena en Bolivia, Ecuador y Perú. La Paz: Cipca, 2008. Aljovín de Losada, Cristóbal y Sinesio López, eds. Historia de las elecciones en el Perú. 2 a ed. Lima: Instituto de Estudios Peruanos, 2018.

Andina Agencia Peruana de Noticias. "Encuesta IEP: 84\% de la población apoya disolución del Congreso". Andina, Sec. Política, 6 octubre 2019, https://andina.pe/agencia/ noticia-encuesta-iep-84-de-poblacion-apoya-disolucion-del-congreso-768815.aspx

Basombrío Iglesias, Carlos y Fernando Rospigliosi. La seguridad y sus instituciones en el Perú a inicios del siglo XXI: reformas democráticas o neomilitarismo. Lima: Instituto de Estudios Peruanos, 2006.

Batalla, Carlos. "El túnel de Polay: la fuga del terrorista que causó estupor en los peruanos en 1990". El Comercio, Sec. Archivo, 7 diciembre 2020, https://elcomercio.pe/ archivo-elcomercio/victor-polay-tunel-fuga-penal-castro-castro-1990-nnsp-noticia/

Beltrán, Isaac y Eduardo Salcedo-Albarán. "Entornos generosos para el crimen: análisis del narcotráfico en Colombia”. Borradores de Método, núm. 49 (agosto 2007): 1-21, https://www.researchgate.net/publication/4829585_Entornos_generosos_para_el_crimen_Analisis_del_narcotrafico_en_Colombia

Bermúdez-Tapia, Manuel. "El control político del Congreso del Perú a las acciones del Ejecutivo en estados de emergencia en ocasión a una pandemia”. Opinión Jurídica 19, núm. 40 (2020): 341-367, https://doi.org/10.22395/ojum.v19n40a17

Bermúdez-Tapia, Manuel. "El procedimiento parlamentario para nombrar altos funcionarios públicos en el Perú”. Estudios Constitucionales 5, núm. 2 (2007): 275-288, https:// www.redalyc.org/pdf/820/82050213.pdf

Bermúdez-Tapia, Manuel. "Public Policies, Pandemic and Corruption: The 'Vacunagate' Case in Peru". Direitos Sociais e Políticas Públicas (Unifafibe) 9, núm. 1 (2021): 948-1008, https://www.unifafibe.com.br/revista/index.php/direitos-sociais-politicas-pub/article/ view/1019

Bueno Victoriano, Javier. "Interdicción contra el transporte aéreo clandestino de derivados cocaínicos desde los departamentos de la Amazonía peruana hacia el extranjero en el período comprendido entre los años 2012 al 2014". Tesis de Maestría, Pontificia Universidad Católica del Perú, 2016. 
Cabieses, Hugo. "El 'milagro de San Martín' y los síndromes del 'desarrollo alternativo' en el Perú", Informes sobre politicas de drogas Transnational Institute, núm. 34 (2010): 1-12, https://www.tni.org/files/download/brief34s.pdf

Caiuby, Beatriz y Henrik Jungaberle, eds. The Internationalization of Ayahuasca. Berlín: Global, 2011.

Canal N. "Edwin Vergara: Fuerza Popular suspendió militancia de congresista vinculado a narco". Canal N, Sec. Actualidad, 11 abril 2018, https://canaln.pe/actualidad/edwinvergara-fuerza-popular-suspendio-militancia-congresista-vinculado-narco-n317769

Canal N. "Vaticano: 'El Perú fue un narcoestado durante el gobierno de Fujimori". Canal N, Sec. Actualidad, 13 enero 2016, https://canaln.pe/actualidad/ demetrio-chavez-penaherrera-vaticano-libertad-alberto-fujimori-n214798

Caro Coria, Dino Carlos y Luis Reyna Alfaro. Compliance y prevención del lavado de activos y del financiamiento del terrorismo: actas del I Foro internacional de compliance y prevención del lavado de activos y del financiamiento del terrorismo. Lima: Centro de Estudios de Derecho Penal Económico y de la Empresa, 2013.

Castilla, Óscar. "Acusado de capo de la droga de Perú junto a financista de Keiko están en la mira de la DEA". Ojo público, Sec. Política, 17 mayo 2016, https://ojo-publico. com/222/acusado-de-capo-de-la-droga-de-peru-junto-financista-de-keiko-estan-enla-mira-de-la-dea

Castro, Jonathan. "Alan García a excabecilla del MRTA, Víctor Polay: date por bien pagado". La República, Sec. Política, 31 julio 2011, https://larepublica.pe/ politica/561161-alan-garcia-a-ex-cabecilla-del-mrta-victor-polay-date-por-bien-pagado/ Cateriano Bellido, Pedro. El caso García. Lima: Planeta, 2017.

Comisión de la Verdad y Reconciliación. Informe final. Lima: CVR, 2003.

Cotler, Julio. ¿̇uevos horizontes para el Perú? Nueva sociedad, núm. 80 (noviembre-diciembre 1985): 115-122, https://nuso.org/articulo/nuevos-horizontes-para-el-peru/

Dammert, Manuel. Fujimori-Montesinos: el Estado mafioso. El poder imagocrático en las sociedades globalizadas. Lima: El Virrey, 2001.

Diario Correo. "Los secuestros del MRTA". Diario Correo, Sec. Lima, 29 septiembre 2015, https://diariocorreo.pe/opinion/los-secuestros-del-mrta-621455/

Díaz, Ingrid, coord. Protocolo de actuación para periodistas en la investigación de casos de corrupción y lavado de activos. Lima: Pontificia Universidad Católica del Perú, 2017.

Dreyfus, Pablo. "Sendero luminoso: ¿un caso de narcoterrorismo?". Revista de la Sociedad Argentina de Análisis Político 5, núm. 8 (1998): 3-32, https://revista.saap.org.ar/ contenido/boletin-1999-otono/ot-dreyfus.pdf

Durand, Francisco. "APRA y narcotráfico". Otra Mirada, Sec. Inicio, 29 abril 2015, bit. ly/3boTBYr 
Espinosa, Óscar. Rondas campesinas y nativas en la Amazonía peruana. Lima: Centro amazónico de antropología y aplicación práctica, 1995.

García, Jaime y Gabriela Stöckli. El rol de las instituciones del Estado en la lucha contra las drogas en los países productores de hoja de coca. Lima: Instituto de Estudios Internacionales, 2014

Grupo de Acción Financiera de Sudamérica. Informe de evaluación mutua antilavado de activos y contra el financiamiento del terrorismo (3ra ronda). Bogotá: Autor, 2008.

La Mula. "Los 18 fujimoristas que blindaron a Hinostroza de la acusación criminal por 'Los cuellos blancos". La Mula, Sec. Redacción, 28 septiembre 2018, https://redaccion. lamula.pe/2018/09/28/los-18-fujimoristas-que-blindaron-a-hinostroza-de-la-acusacion -criminal-por-los-cuellos-blancos/redaccionmulera/

La República. "Gerald Oropeza y sus nexos con el APRA". La República, Sec. Política, 24 abril 2015, https://larepublica.pe/politica/872094-gerald-oropeza-y-sus-nexos-conel-apra-imagen-interactiva/?ref=lre 39cHdJA

La República. "Los cuellos blancos del puerto: el origen del nombre de la organización criminal". La República, Sec. Política, 7 julio 2019, https://larepublica.pe/politica/2019/07/07/ los-cuellos-blancos-del-puerto-el-origen-del-nombre-de-la-organizacion-criminal/

Lynch, Nicolás. Una tragedia sin héroes: la derrota de los partidos y el origen de los independientes, Perú 1980-1992. Lima: Universidad Nacional Mayor de San Marcos, 1999.

Maldonado Paredes, Antonio. "Un falso dilema en la lucha contra los delitos de cuello blanco". Testimonio, núm. 125 (2018): 8-9.

Manrique-López, Hernán. "Política de drogas y narcotráfico en el Perú: del triunfalismo peruano al laberinto de la cocaína". Cultura y Droga 20, núm. 22 (2015): 64-85, http://vip.ucaldas.edu.co/culturaydroga/downloads/Culturaydroga20(22)_04.pdf

Marcus-Delgado, Jane y Martín Tanaka. Lecciones del final del fujimorismo: la legitimidad presidencial y la acción política. Lima: Instituto de Estudios Peruanos, 2001.

Meléndez Guerrero, Carlos. El mal menor: vínculos políticos en el Perú posterior al colapso del sistema de partidos. Lima: Instituto de Estudios Peruanos, 2019.

Melgar, Sandy. "La red de la bestia: la construcción de redes de corrupción en los gobiernos subnacionales, el caso de César Álvarez en Áncash”. Revista de Ciencia Política y Gobierno 4, núm. 8 (2017): 139-165, https://doi.org/10.18800/rcpg.201702.006

Mella, Romina. "Secretos del narcoavión". IDL-Reporteros, Sec. Exclusivo, 4 junio 2011 , https://www.idl-reporteros.pe/secretos-del-narcoavion/

Montoya Rojas, Rodrigues. "El Perú después de 15 años de violencia". Estudos Avançados 11, núm. 29 (1997): 287-308, https://www.researchgate.net/publication/250982679 _El_Peru_despues_de_15_anos_de_violencia_1980-1995

Montoya, Yvan. "La agonía de la lucha contra la corrupción en el Perú". Proyecto Anticorrupción 47, núm. 10 (noviembre 2015): 5-7, http://cdn01.pucp.education/idehpucp/wp-content/ uploads/2017/07/01191226/2015_boletin54.pdf 
MRT. "Cocaleros realizan 'marcha de sacrificio' en Pert". MRT, Sec. Noticias, 11 julio 2005, https://www.mrt.com/news/amp/Cocaleros-realizan-marcha-de-sacrificio-enPert-7699724.php

Núñez, Adolfo. "El narcotráfico en el Perú: estrategias conjuntas de las fuerzas armadas y la policía nacional para su erradicación”. Boletín de información, núm. 260 (1999): 79-85, https://dialnet.unirioja.es/servlet/articulo?codigo=4626338

Ojeda Acosta, Manuel Jesús. "El proceso de transformación de la relación política entre el Partido Nacionalista Peruano y el movimiento cocalero de la zona del VRAE, durante la campaña electoral del 2011". Tesis de Maestría, Pontificia Universidad Católica del Perú, 2012.

Ortiz, Claudia. "Decisión de juez Hinostroza permitió archivar caso de Joaquín Ramírez". La República, Sec. Política, 8 julio 2018, https://larepublica.pe/politica/1275185-cesarhinostroza-permitio-archivar-caso-lavado-activos-joaquin-ramirez/

Pásara, Luis. Perú ante los desafíos del siglo XXI. Lima: Pontificia Universidad Católica del Perú, 2011.

Pereira, Diego. "El fujimorismo blinda a Pedro Chávarry por sustraer documentos de oficinas lacradas". Útero, Sec. Curwen, 28 mayo 2019, http://utero.pe/2019/05/28/ el-fujimorismo-blinda-a-pedro-chavarry-por-sustraer-documentos-de-oficinaslacradas-pero-lo-peor-viene-despues/

Perú 21. "Jaime Antezana: "Hay 14 congresistas vinculados al narcotráfico". Perú 21, Sec. Política, 5 septiembre 2014, https://peru21.pe/politica/jaime-antezana-hay -14-congresistas-vinculados-narcotrafico-183732-noticia/

Perúal día. "Juicio oral para Nancy Obregóny Elsa Malpartida". Perúal día, Sec. Nacional, 21 septiembre 2017, https://www.perualdia.pe/juicio-oral-para-nancy-obregon-y-elsa-malpartida/

Perú, Congreso de la República. "Recomiendan destituir a tres congresistas". http://www. congreso.gob.pe/index.php?K=263\&id=11173/noticias/RECOMIENDAN-DESTITUIRA-TRES-CONGRESISTAS (acceso abril 25, 2020).

Perú, Congreso de la República. "Secretos del narcoavión”. http://www2.congreso.gob.pe/ Sicr/GrupParlamentarios/bloquepopular.nsf/vf12web/D404A9111EB44D58052578 A70051A794/\$FILE/Secretos.pdf (acceso marzo 17, 2020).

Perú, Congreso de la República. Comisión de investigación de los narcoindultos en el Congreso de la República del Perú, “Comisión Montenegro”. Lima: Congreso de la República, 2016.

Perú, Ministerio Público, Fiscalía de la Nación. "Fiscalía desarticula organización criminal 'Los cuellos blancos del puerto' en el Callao a partir de escuchas telefónicas legales. https://www.gob.pe/institucion/mpfn/noticias/436488-fiscalia-desarticula-organizacioncriminal-los-cuellos-blancos-del-puerto-en-el-callao-a-partir-de-escuchas-telefonicaslegales (acceso marzo 20, 2020). 
Puente Aba, Luz María. El delito de financiación ilegal de partidos políticos. Valencia: Tirant lo Blanch, 2017.

Quiroz, Alfonso. Historia de la corrupción en el Perú. 3a ed. Lima: Instituto de Estudio Peruanos, 2019.

Raffo, Leonardo y Diego Gómez Calderón. "Redes criminales y corrupción en la era del microtráfico y el narcomenudeo". Revista de Economía Institucional 19, núm. 37 (julio-diciembre 2017): 227-261, https://papers.ssrn.com/sol3/papers.cfm?abstract_id=3114208

Ramírez, Reynaldo. Los jueces de Montesinos: la red montesinita en el poder Judicial 1990-2000. Lima: Academia de Magísteres y Doctores del Perú, 2002.

Redacción. "Fujimorismo activa denuncias por encubrimiento contra Pedro Chávarry”. Gestión, Sec. Política, 6 octubre 2019, https://gestion.pe/peru/politica/ fujimorismo-archiva-denuncias-encubrimiento-pedro-chavarry-269731-noticia/

Rodríguez Alegre, Iván. Vladimiro Montesinos y el poder político en el mandato de Alberto Fujimori. Lima: San Marcos, 2007.

Rosen, Jonathan y Hanna Samir Kassab. Fragile States in the Americas. Lanham: Lexington Books, 2017.

Rospigliosi, Fernando, Cecilia Blondet y José Antonio Lloréns Amico. El consumo tradicional de la hoja de coca en el Perú. Lima: Instituto de Estudios Peruanos, 2004.

RPP. "Abogado de Joaquín Ramírez sostuvo reunión con César Hinostroza y Walter Ríos". RPP Noticias, Sec. Redacción, 12 agosto 2018, https://rpp.pe/politica/actualidad/ abogado-de-joaquin-ramirez-sostuvo-reunion-con-cesar-hinostroza-y-walter-riosnoticia-1142833

Sánchez, Rubén, Juan Carlos Ruiz, Stéphanie Lavaux, Francesca Ramos, Manuel José Bonett, Rocío Pachón, Federmán Rodríguez, Andrés Otálvaro, Ivonne Duarte, Rubén Machuca y Carlos Suárez. Seguridades en construcción en América Latina. Tomo I: El círculo de Colombia, Brasil, Ecuador, Panamá, Perú y Venezuela. Bogotá: Universidad del Rosario, 2005.

Santana Hernández, Adalberto. El narcotráfico en América Latina. Ciudad de México: Siglo XXI, 2004.

Saravia, Gerardo y Patricia Wiesse. "Un hueso duro de roer". Ideele, núm. 255 (2013), https:// revistaideele.com/ideele/content/un-hueso-duro-de-roer (acceso marzo 30, 2021).

Soberón Garrido, Ricardo. "Distorsiones y prejuicios sobre narcotráfico y terrorismo: la selva alta y el Estado". Quehacer, núm. 181 (enero 2011): 38, https://go.gale.com/ps/ anonymous?id=GALE\% 7CA254260894\&sid=googleScholar\&v=2.1\&it=r\&linkacce $\mathrm{ss}=\mathrm{abs} \& \mathrm{issn}=02509806 \& \mathrm{p}=\mathrm{IFME} \& \mathrm{sw}=\mathrm{W}$

Stöckli, Gabriela. "Narcotráfico en el Perú: ¿Lucha contextualizada o contexto en lucha?". La Colmena, núm. 7 (2014): 8-17, http://revistas.pucp.edu.pe/index.php/lacolmena/ article/view/12509 
Tanaka, Martín. La situación de la democracia en Colombia, Perú y Venezuela a inicios de siglo. Lima: Comisión andina de juristas, 2002.

Tokatlián, Juan Gabriel. Globalización, narcotráfico y violencia: siete ensayos sobre Colombia. Bogotá: Grupo Editorial Norma, 2000.

Tuesta Soldevilla, Fernando. Perú: elecciones 2016. Un país dividido y un resultado inesperado. Lima: Pontificia Universidad Católica del Perú, 2017.

Ugaz Sánchez Moreno, José Carlos. Prensa juzgada: treinta años de juicios a periodistas peruanos (1966-1999). Lima: Pontificia Universidad Católica del Perú, 1999.

Universidad Privada San Juan Bautista. "Análisis del impacto político, económico y social de la corrupción en la gestión pública. Proyecto de investigación desarrollado en la Facultad de Derecho de la Universidad Privada San Juan Bautista aprobado por Resolución de Vicerrectorado de Investigación N. o 017-2021-VRI-UPSJB", https:// investigacion.upsjb.edu.pe/docentes_investigacion/ (acceso febrero 17, 2020).

Vigo, Manuel. "Kenji Fujimori, Most Popular Congressman. Linked to Drug Trade", Telesur, Sec. Latin America, 10 abril 2016, https://www.telesurenglish.net/news/Kenji-FujimoriMost-Popular-Congressman-Linked-to-Drug-Trade-20160410-0039.html

Wayka. "Existen 21 narco-congresistas según investigador Antezana". https://wayka.pe/ existirian-al-menos-21-narco-congresistas-segun-investigador-antezana/ (acceso mayo 12, 2020).

Youngers, Coletta y Eileen Rosin. Drogas y democracia en América Latina: el impacto de la política de Estados Unidos. Buenos Aires: Biblos, 2005.

Zevallos Trigoso, Nicolás. "Dinámicas locales en torno al cultivo de hoja de coca: elementos para el estudio desde el mercado ilegal de la cocaína". Revista de Ciencia Política y Gobierno 4, núm. 7 (2017): 9-29, http://revistas.pucp.edu.pe/index.php/cienciapolitica/ article/view/19299

Zevallos Trigoso, Nicolás. Control y defensa del cultivo de hoja de coca en el Perú. Lima: Pontificia Universidad Católica del Perú, 2016.

Zúñiga Rodríguez, Laura. "La captura del Estado peruano por el narcotráfico: el caso de los 'Cuello blanco del puerto". Revista de Estudios en Seguridad Internacional 6, núm. 2 (2020): 175-191. 